\title{
Ethnic Value in South Kalimantan Madihin Text: Ethnopoetical Review
}

\author{
Haswinda Harpriyanti ${ }^{1}$, Setya Yuwana ${ }^{2}$, Anas Ahmadi ${ }^{3}$, Udjang Pairin ${ }^{4}$, Darni ${ }^{5}$, Suhartono ${ }^{6}$ \\ \{haswinda.19024@mhs.unesa.ac.id ${ }^{1}$, setyayuwana@unesa.ac.id²; anasahmadi@unesa.ac.id ${ }^{3}$; \\ udjangpairin@unesa.ac.id ${ }^{4}$; darni@unesa.ac.id ${ }^{5}$; suhartono@unesa.ac.id $\left.{ }^{6}\right\}$ \\ Universitas Negeri Surabaya, Indonesia ${ }^{123456}$
}

\begin{abstract}
Madihin was one of the oral literatures in South Kalimantan, in the form of poetry, containing verses, and was pronounced accompanied by music produced from a musical instrument called tarbang. Madihin was considered as one of the local entertainments which was rich in humor. However, the Madihin text also contains ethnic values which are a reflection for the Banjar community. Through ethnopoetic studies, this study aims to describe ethnic values in the Madihin text. Ethnopoetics was used to study Madihin text that has been staged by reflecting on them in the daily life of the Banjar people. The data sources of this research were the pemadihin or people who often sing Madihin in various events. The results of this study indicated that in the Madihin text, cultural values were found, namely mutual respect, the tradition of thinking about the gift or adjudication of marriage, the Banjar art forms, the culture of the Banjarmasin River, the kinship system, and the language system.
\end{abstract}

Keywords: ethnic values, Madihin text, South Kalimantan..

Nilai Etnik dalam Teks Madihin Kalimantan Selatan: Tinjauan Etnopuitika

\begin{abstract}
Abstrak. Madihin merupakan salah satu sastra lisan di Kalimantan Selatan, berbentuk puisi, berisikan syair-syair, dan diucapkan dengan diiringi lantunan musik yang dihasilkan dari alat musik bernama tarbang. Madihin dianggap sebagai salah satu hiburan lokal yang kaya akan humor. Namun, di dalam teks Madihin juga terselip nilai etnik yang menjadi refleksi bagi masyarakat Banjar. Melalui kajian etnopuitika, penelitian ini bertujuan untuk mendeskripsikan nilai etnik dalam teks Madihin. Etnopuitika digunakan untuk mengkaji teks-teks Madihin yang pernah dipentaskan dengan merefleksikannya pada kehidupan sehari-hari masyarakat Banjar. Sumber data penelitian ini adalah pemadihin atau orang yang sering melantunkan Madihin dalam berbagai acara. Hasil penelitian ini menunjukkan bahwa dalam teks Madihin ditemukan nilai budaya, yaitu saling menghargai dan menghormati, tradisi berpikir tentang hadiah atau jujuran perkawinan, bentuk-bentuk kesenian Banjar, budaya Sungai Banjarmasin, sistem kekerabatan, dan sistem bahasa.
\end{abstract}

Kata kunci: nilai etnik, teks Madihin, Kalimantan Selatan. 


\section{Pendahuluan}

Kalimantan Selatan pada dasarnya kaya akan sastra, baik lisan maupun tulis. Sastra di Kalimantan Selatan sering disebut dengan Sastra Banjar. Madihin merupakan salah satu bentuk sastra lisan yang dimiliki oleh masyarakat Banjar Kalimantan Selatan. Seperti yang dijelaskan oleh Rafiek [1], madihin sebagai salah satu ragam sastera lisan Banjar dan muatan tempatan di Kalimantan Selatan yang dulunya sebagai hiburan pelepas lelah selesai tuai, sebagai hiburan di malam hari selepas majlis perkahwinan. Eksistensi Madihin sendiri di kalangan masyarakat Banjar masih sangat baik, sebab memang Madihin dapat dinikmati oleh berbagai kalangan dari anak muda hingga orang tua. Namun demikian Madihin tetap harus dijaga kelestariannya, salah satunya dengan melakukan penelitian-penelitian. Kini, Madihin juga dipergelarkan pada saat hari besar nasional. Madihin berisikan syair-syair yang berbentuk pantun dan dibawakan oleh pamadihinan dengan pakaian adat Banjar sambil memukul tarbang (sejenis rebana). Madihin sering mengundang tawa dan decak kagum penontonnya karena bahasa pantunnya yang mengandung humor. Meskipun demikian, Madihin tidak sekedar membungkus humor, namun juga nilai-nilai etnik masyarakat pemiliknya. Memahami nilai etnik kini menjadi penting dilakukan, guna terus memberikan ruang eksistensi pada budaya itu sendiri, serta sebagai bentuk kebanggaan terhadap warisan nenek moyang di era global.

Penelitian yang relevan pernah dilakukan oleh Leha [2] tentang kajian nilai religi pada Madihin karya Jhon Tralala. Hasil penelitian ini menunjukkan bahwa Madihin, sebagai sastra lisan Banjar, mengandung nilai religius yang dapat diaplikasikan dalam kehidupan sehari-hari, berupa iman kepada Allah, syukur kepada Allah [1], taat kepada Allah, sopan santun, cinta damai dan saling menghormati. Penelitian lain tentang Madihin juga pernah dilakukan oleh [1] yang membahas tentang Pantun Madihin, kajian ciri, struktur pementasan, kreativitas pemadihin pembangunan dan pembinaannya di Kalimantan Selatan. Hasil penelitian ini menjelaskan bahwa Pantun Madihin sebagai salah satu sastra lisan Banjar di Kalimantan Selatan mempunyai ciri dan struktur pementasan yang khas. Kekhasan itu terlihat dari pantun madihin yang boleh juga menggunakan syair dalam pementasannya. Struktur pementasan Madihin meliputi pembukaan, memasang tabi, menguran, dan penutup. Kreativitas pemain Madihin dalam membuat pantun Madihin dan kemahiran memukul terbang (sejenis rebana) sangat diperlukan. Dalam hal pembangunan dan pembinaan madihin, pemerintah daerah, agensi berkaitan, dan masyarakat termasuk institusi pendidikan dan media televisi sangat menyokong usaha mempertahankan dan pemeliharaan Pantun Madihin.

Penelitian lain juga dilakukan oleh Widiyanti dan Sunarto [3]. Penelitian tersebut meyimpulkan bahwa madihin terjadi akibat adanya interaksi sosial yang terjadi antara pemadihin dan penikmat. Selain itu, ada pula penelitian yang membahas tentang Makna Syair Madihin Baintan Kebudayaan Banjarmasin Menggunakan Pendekatan Strukturalisme oleh Muhlisin, dkk. [4]. Hasil penelitian tersebut mengatakan bahwa kesenian tradisional Baintan memiliki makna konotasi dan denotasi. Makna Konotasi dari Baintan Baintan tersebut yakni terjemahan bahasa Indonesia yang belum dimaknai, sedangkan makna denotasi dari Baintan Baintan tersebut yakni terdapat makna gurauan dan makna budaya yang memiliki makna sebagai kegiatan hiburan juga makna untuk memperkenalkan identitas daerah pemadihin. Dari beberapa penelitian di atas yang pernah dilakukan tentang Madihin, diketahui bahwa Madihin dibahas dari banyak segi, baik dari segi nilai religi yang ada di dalam madihin, struktur pantunnya dengan struktur pementasannya, kreativitas musik dan tindakan sosial di dalamnya, dan kemudian makna syair Madihin dengan pendekatan strukturalisme. Sedangkan, penelitian tentang nilai etnik yang terkandung dalam teks Madihin, sepengetahuan peneliti masih beum ditemukan. Dengan demikian jelas, penelitian ini berbeda dengan penelitian sebelumnya 
sebab, pada penelitian ini akan membahas tentang bagaimana makna nilai etnik yang terdapat dalam Madihin sebagai bentuk dari refleksi budaya masyarakat Banjar. Struktur teks Madihin yang khas membungkus dengan indah nilai-nilai etnik masyarakat Banjar. Hal tersebut akan dikaji dalam penelitian ini, ditinjau dari sisi etnografi sebagai pendekatan yang akan mengungkap bagaimana budaya masyarakatnya tergambar di dalam teks Madihin dengan fokus penelitian "Nilai Etnik dalam Teks Madihin Kalimantan Selatan Tinjauan Etnosemiotika."

Madihin adalah kesenian tradisi suku banjar, Kalimantan Selatan. Madihin termasuk dalam folklor Banjar yakni folklor sebagian lisan. Madihin berasal dari kata madah artinya syair-syair yang dinyanyikan. Madah dalam khasanah puisi Indonesia lama yang juga merujuk pada sejenis puisi yang penuturannya dilakukan dengan cara dinyanyikan dengan diiringi musik dari tebang. Pada kalangan masyarakat Kalimantan Selatan sendiri Madihin salah satunya dipentaskan sebagai sarana hiburan. Hal ini sejalan dengan pendapat Sulistyowati dan Ganie [5] yang menjelaskan bahwa madihin adalah puisi rakyat bertipe hiburan yang dilisankan atau dituliskan dalam bahasa Banjar dengan bentuk fisik dan bentuk mental tertentu sesuai dengan konvensi khusus yang berlaku dalam khasanah folklor Banjar.

Terkait foklor Banjar, Effendi [6] mengatakan bahwa Madihin merupakan bagian dari sastra lisan. Ia menjelaskan, folklor sebagian lisan adalah folklor yang di samping dituturkan juga menggunakan alat bantu lain seperti gendang (terbang) dan bunyi-bunyian lain, atau juga dibantu dengan gerakan anggota badan, seperti mimik, tari-tarian, mamang (gumam), juga benda-benda yang dianggap dapat memperkuat kekuatan tuturan dan mamang. Dengan demikian, jelas sudah bahwa Madihin merupakan bagian dari sastra lisan Banjar yang media penyampaianya adalah bahasa Banjar.

Madihin, selain bertujuan untuk menghibur, juga memiliki fungsi lain seperti menyampaikan pesan-pesan yang terkandung dalam syair madihin yang dibawakan oleh pemadihin. Hal ini diperkuat oleh pendapat Hasuna dan Lismayanti [7], bahwa Madihin termasuk salah satu karya yang juga telah mempunyai ruang lingkup yang cukup luas. Ada beberapa unsur yang terdapat dalam sastra lisan Madihin, di antaranya unsur pendidikan, unsur moral, unsur agama, dan lain-lain. Unsur-unsur yang dimaksud merupakan hal yang pokok dalam madihin. Hal itu terlihat dari syair atau pantun yang dibawakan oleh pamadihinan selalu mengandung makna tersendiri. Dari berbagai pendapat yang telah dijelaskan dapat dikatakan bahwa Madihin merupakan kesenian lisan tradisional Banjar yang tidak hanya bernilai seni, tetapi juga memiliki tujuan untuk menyampaikan pesan kepada pendengar melalui syair yang dibawakan oleh pemadihin. Dengan demikian, fokus penelitian ini adalah bagaimana nilai etnik dalam teks Madihin, sehingga tujuannya adalah untuk mengungkap nilai makna yang ada di dalam teks Madihin Kalimantan Selatan.

Hasan [8] menjelaskan, makna budaya dalam sebuah bahasa tidak berlaku universal, sehingga perlu pemahaman makna untuk mengetahui maksud dari bahasa tersebut. Bustan [9] mengatakan, untuk memahami makna budaya perlu relevansi dengan konteks terjadinya bahasa itu. Makna hasil dari kesepakatan dan nilai etnik di sini akan merujuk kepada sebuah pemahaman yang mendalam, memiliki nilai kepercayaan, dan masih dijalankan oleh masyaraat dalam tataran tradisi budaya.

Istilah "etnopuitika" yang terdiri atas prefiks etno dan kata dasar puitika, mengacu pada dua hal. Etno, secara etimologis, berkaitan erat dengan kata etnik atau etnis, yang mengacu pada pada sebuah masyarakat sebagai suatu kelompok budaya. Sedangkan puitika dalam pengertian struktural, sebagaimana dikemukakan oleh Sahril [10], mengacu pada bahasa puitis. Namun demikian, dalam penelitian ini, puitika tidak mengacu pada teks puisi, 
melainkan merujuk pada teks Madihin Kalimantan Selatan yang pernah ditampilkan oleh pemadihin.

Etnopuitika diperkenalkan oleh Rothenberg pada tahun 1968 melalui jurnal Alcheringa. Dalam perkembangan selanjutnya ada dua ciri utama yang menandai etnopuitika. Sherzer [11] menjelaskan dua hal terkait etnopuitika. Pertama, etnopuitika memfokuskan diri pada pentas sastra. Dalam hal ini etnopuitika dapat dipandang sebagai puitika-pentas, yang merupakan titik temu dari berbagai disiplin ilmu linguitik, antopologi, sastra lisan, dan folklore. Kedua, etnopuitika berusaha mempelajari makna pentas sastra serta implikasinya dengan lebih dahulu memahami pengetahuan lokal. Hal tersebut selaras dengan pendapat Pattipeiluhu dan Sudikan [12], bahwa etnopuitika mementingkan wawasan lokal berupa budaya yang tersimpan dalam masyarakat dan peran masyarakat sebagai makhluk sosial, untuk mengekspresikan budaya dengan cara berpikir dan bertindak, cara pandang, tingkat pengetahuan, bentuk seni, dan sebagainya. Subrata [13] menjelaskan bahwa etnopuitika mengandung dua unsur utama yaitu (1) materi formal yang berupa bahasa dan (2) suara. Sebab keduanya bernuansa puitis, maka etnopuitika mengacu pada keindahan bahasa susastra dan suara. Kadarisman [14] mengusulkan fitur puisi yang universal (the universality of poetics features). Materi formal berupa bahasa susastra ini berupa bahasa tulis dan lisan. Dalam konteks Madihin, bahasa yang menjadi fokus adalah bahasa tulis. Madihin bukan hanya sekedar pertunjukan seni lisan tradisonal Banjar, namun ada banyak hal yang dapat diungkap melalui Madihin dan memberikan refleksi bagi masyarakat sebagai penikmat dari Madihin itu sendiri. Salah satunya adalah untuk mengungkap makna nilai etnik dalam teks Madihin sebab sebuah keindahan tidak cukup hanya dilihat dan didengar melalui pancaindera. Keindahan juga dapat lihat melalui kebermaknaan nilai budaya masyarakat yang dibungkus secara indah melalui teks demi tercapainya tujuan dari penyampaian teks tersebut kepada khalayak.

\section{Metode}

Pendekatan yang digunakan dalam penelitian ini adalah pendekatan kualitatif dengan tinjauan etnografi. Kualitatif di sini berarti peneliti akan memberikan gambaran hasil penelitian dengan sejelas-jelasnya secara objektif melalui ungkapan kalimat-kalimat yang jelas. Creswell menjelaskan bahwa etnografi berusaha meneliti suatu kelompok kebudayaan tertentu berdasarkan terutama pada pengamatan dan kehadiran peneliti di lapangan. Dengan demikian, penelitian ini mencoba mengungkapkan secara detail tentang nilai etnik dalam teks madihin Kalimantan Selatan melalui tinjauan etnopuitika [15].

\section{Hasil Pembahasan}

\subsection{Makna Nilai Etnik dalam Teks Madihin Kalimantan Selatan}

\section{Data 1}

Tema "Safrah Amal"

Karya Ahmad Fauzan 
Baik nang di muka atau nang di balakang Baik nang di kiri atau jua di kanan

Ulunlah ini handak bamadihinan Di dalam acara safrah amal bangaran Ini bertempat MTs. Sairussalam Salamat manyimak jua manyaksiakan

Pertama-tama kita hormati samua Bapa Bupati kabupaten Batola Kepala Desa jua Sinar Barunya Penceramah kita muliakan bersama

Kada tatinggal seluruh panitia Lawan jua ini siswi dan siswa Ditambah lagi ini masyarakatnya Para pengunjung inilah acara

Tepuk tangan gasan kita samua

Sabalum batarus madihin ulun bawa Ulun ucapkan ini terima kasihnya

Pada ketua inilah panitia

Atas undangan ulun menghibur acara

Bapa Rafi'i sidinlah bernama

Nang awak gagah jualah berwibawa

Jadi panutan itulah samuanya

Kita doakan smoga selalu bahagia

Hidup bahagia di akhirat masuk surga

Ulun lihat pengunjung samuanya Ada lelaki ada jua wanita

Ada nang anum ada jua nang tuha

Ada kakanakan ada jua pamuda

Ada nang mancung ada nang pesek hidungnya Ada tinggi ada nang endek jua

Ada nang putih ada nang kadap jua

Mun nang kadap kalihatan gigi haja

Sabalum jauh madihin ulun bawakan Terlebih dulu ulunlah perkenalan

Ulun Ahmad Fauzan inilah bangaran

Nang masih anum jua masih sendirian

Jadi tenang haja itu nang babinian Apalagi itu nang babujangan Mun berminat bisa haja diungkapkan

Mun bataksir no hape bahurupan

Para hadirin itu nang ada di sini Ini masih tentang ulun sendiri Nang Simpang Arja itulah didiami
[Baik yang di depan atau yang di belakang]

[Baik yang di kiri maupun di kanan]

[Saya ingin bemadihinan]

[Dalam acara safrah amal bernama]

[Ini bertempat MTs. Sairussalam]

[Selamat menyimak dan menyaksikan]

[Pertama-tama kita hormati semua]

[Bapak Bupati Kabupaten Batola]

[Kepala Desa juga Sinar Barunya]

[Penceramah kita muliakan bersama]

[Tidak tertinggal seluruh panitia] [Dengan juga ini siswi dan siswa] [Ditambah lagi ini masyarakatnya]

[Para pengunjung inilah acara]

[Tepuk tangan untuk kita semua]

[Sebelum berterus madihin saya bawa]

[Saya ucapkan ini terima kasihnya]

[Pada ketua inilah panitia]

[Atas undangan saya menghibur acara]

[Bapak Rafi'i beliaulah bernama]

[Yang badangagah jugalah berwibawa]

[Jadi panutan itulah semuanya]

[Kita doakan semoga selalu bahagia]

[Hidup bahagia di akhirat masuk surga]

[Saya lihat pengunjung semuanya]

[Ada lelaki ada juga wanita]

[Ada yang muda ada juga yang tua]

[Ada anak-anak ada juga remaja]

[Ada yang mancung ada yang pesek hidungnya]

[Ada tinggi ada yang pendek juga]

[Ada yang putih ada yang hitam juga]

[Jika yang hitam terlihat giginya saja]

[Sebelum jauh madhin saya bawakan]

[Terlebih dahulu sayalah perkenalan]

[Saya Ahmad Fauzan inilah bernama]

[Yang masih muda juga masih sendirian]

[Jadi tenang saja itu yang perempuan]

[Apalagi itu yang bujangan]

[Jika berminat bisa saja diungkapkan]

[Jika tertarik nomor telepon bertukaran]

[Para hadirin itu yang ada di sini]

[Ini masih tentang saya sendiri]

[Yang Simpang Arja itulah ditempati] 
Urang Simpang Arja dasar bungas dilihati Mun kada parcaya cuba lihat ka sini Kada manyasal amun diambil laki

Para pengunjung inilah sekalian Nang babujangan lalakian babinian Ini lalakian banyak nang liwar tampan Jua babinian langkar-langkar babanaran

Inya takuring dada ulun galudupan Apalagi mun inya bari kijipan Maulah hati ulun kada karuan Munnya ulun bulik bisa tajual pahumaan

Masih babinian ini babujangannya Nang langkar-langkar ini luar biasa Nang dilelek oleh lalakiannya Mun pian dirayu jangan tapi percaya

Hati-hati pian kana modusnya Padahal sudah baisi pacar lima Mun pian handak baik lawan nang di muka Nang bamadihin inilah orangnya Dijamin bahagia ulun pasti setia

Wahini zaman urang katuju baselfie Apalagi ini nang bini-bini

Hape harat jualah mambagusi

Lain banar lawan urangnya asl

Dibungasi pakailah aplikasi

Muha diputihi gincunya ditabali

Lihat hasilnya miriplah Syahrini

Imbah tatamu pina mambalakangi

Lihat baju itulah pina aksi

Imbah bapaling kada lain nini-nini

Ulun lihat lagi penonton samuanya Ini pengunjung itu lalakiannya

Nang ulun lihat banyak mamiripannya

Ada nang mirip lawanlah Anjasmara

Ada jua potongan Rhoma Irama Ada jua kaya artis sanitrunnya

Nang awak putih barasih sampai ka muha

Dinampaki kada lain panau wara

Ini acara bagus luar biasa

Tentulah itu gasan kita samua

Untuk beramal itulah jariyahnya

Gasan sangu itu di akhiratnya

Ini acara jua banyak manfaatnya
[Orang Simpang Arja memang tampan dicermati]

[Jika tidak percaya coba lihat ke sini]

[Tidak menyesal jika diambil suami]

[Para pengunjung inilah semuanya] [Yang bujangan laki-laki dan perempuan]

[Ini lelaki banyak yang sangat tampan]

[Juga perempuan sangat cantik-cantik]

[Dia tersenyum dada saya berdebar-debar]

[Apalagi jika dia beri kedipan]

[Membuat hati saya tidak karuan]

[Jika saya pulang bisa terjual pesawahan]

[Masih perempuan ini bujang-bujangnya]

[Yang cantik-cantik ini luar biasa]

[Yang dilirik oleh laki-lakinya]

[Jika Anda dirayu jangan tapi percaya]

[Hati-hati Anda terkena modusnya]

[Ternyata sudah punya pacar lima]

[Jika Anda baik dengan yang di muka]

[Yang bermadihin inilah orangnya]

[Dijamin bahagia saya pasti setia]

[Sekarang zaman orang senang berselfi]

[Apalagi ini yang perempuan]

[Hp canggih jugalah yang membaguskan]

[Lain sekali dengan orang yang asli]

[Dipercantik menggunakan aplikasi]

[Wajah diputihkan lipstik ditebalkan]

[Lihat hasilnya mirip dengan Syahrini]

[Setelah bertemu agak membelakangi]

[Lihat bajunya sangat cantik]

[Setelah berpaling tidak lain nenek-nenek]

[Saya lihat penonton semuanya]

[Ini pengunjung lelakinya]

[Yang saya lihat banyak yang miripnya]

[Ada yang mirip dengan Anjasmara]

[Ada juga seperti Rhoma Irama]

[Ada juga seperti artis Korea]

[Yang badan putih bersih sampai ke wajah]

[Diperhatikan lagi ternyata panau saja]

[Ini acara bagus luar biasa]

[Tentulah itu untuk kita semua]

[Untuk beramal itulah jariyahnya]

[Untuk bekal di akhiratnya]

[Ini acara juga banyak manfaatnya] 
Mudahan berkah gasan kita samua

Tentulah itu jadi ladang pahala

Mudahan lancar sampai selesai acara

Sampai di sini ulun mambawa akan

Ini madihin gasan pian barataan

Dari ulun masih banyak kakurangan

Ulun minta maaf bila ada kasalahan

Kata-kata itu nang kurang nyaman

Ulun hanya sakadar bagayaan

Ambil nang baik buruk ka pinggirakan

Minta halal minta ridho barataan

Assalamualaikum kini ulun ucapkan
[Semoga berkah untuk kita semua]

[Tentu saja itu jadi ladang pahala]

[Semoga lancar sampai selesai acara]

[Sampai di sini saya bawakan]

[Ini madihin untuk Anda semuanya]

[Dari Saya masih banyak kekurangan]

[Saya minta maaf jika ada kesalahan]

[Kata-kata yang kurang nyaman]

[Saya hanya sekedar bercanda]

[Ambil yang baik buruknya dipinggirkan]

[Minta halal minta ridho smeuanya]

[Assamualaikum kini saya ucapkan]

Keberadaan Madihin selain sebagai tradisi lisan yang turun temurun, penghibur bagi masyarakat pemiliknya, juga dapat dijadikan media penyampai nasihat dan nilai-nilai budaya sebagai bentuk ekspresi dari masyarakat Banjar itu sendiri. Dalam data 1 tersebut terdapat nilai budaya antara lain sebagai berikut.

\section{a. Menghargai dan menghormati}

Sikap menghargai dan menghormati tergambar jelas di dalam teks Madihin pada bait ke 1, 3, 4, 5, dan 6. Pada bait pertama jelas pemadihin mengucapkan salam kepada seluruh pengunjung yang hadir dalam acara safrah amal "Assalamualaikum ulun maucap salam". Hal tersebut menunjukkan sebuah sikap menghormati kepada seluruh pengunjung yang hadir. Pada bait ketiga pemadihin atau orang yang menyampaikan madihin juga mengucapkan salam hormat untuk semua orang-orang yang memiliki jabatan yang datang pada acara tersebut seperti bapak Bupati, Kepada Desa, dan Penceramah "Pertama-tama kita hormati samua ...". Selanjutnya pada bait keempat dan lima juga pemadihin mengucapkan terima kasih kepada seluruh panitia sebagai bentuk penghargaan, sebab telah diberikan kesempatan baginya untuk mengisi acara tersebut dan menghibur seluruh pengunjung yang hadir. Pada bait keenam terlihat juga pada teks madihin bahwa pemadihin menyampaikan rasa hormatnya kepada salah seorang bapak yang dianggap sebagai orang yang disegani, dihormati, dan menjadi panutan ia juga menyampaikan sepenggal doa untuk beliau agar senantiasa bahagia serta kelak di akhihat masuk surga "Kita doakan smoga selalu bahagia, Hidup bahagia di akhirat masuk surga". Dari beberapa bait yang telah dibahas, jelas sekali terlihat bentuk sikap menghargai dan menghormati kepada sesama terlebih kepada orang yang lebih tua. Ini adalah salah satu nilai budaya yang dimiliki masyarakat Banjar dan telah ditanamkan secara turun temurun. Masyarakat Banjar mayoritas beragama muslim dan dikenal cukup agamamis. Hal ini tercermin jelas dalam kehidupan sehari-hari mereka sangat yang menyegani para kaum ulama dan sangat bersikap merendah dengan orang yang lebih tua di sekitar mereka. Oleh sebab itu, hal ini juga tergambar jelas di dalam teks Madihin yang dibawakan oleh pemadihin dalam acara safrah amal pada data 1 tersebut.

\section{b. Tradisi berpikir (jujuran perkawinan)}

Tradisi berpikir di sini adalah kebiasaan turun temurun dari nenek moyang tentang sesuatu yang masih dilakukan oleh masyarakatnya yang dianggap paling baik dan benar. Hal 
ini berkaitan dengan jujuran penikahan. Nilai etnik ini tersirat dalam teks Madihin pada bait ketigabelas “...Maulah hati ulun kada karuan, Munnya ulun bulik bisa tajual pahumaan”. Jika mengacu pada Indonesia yang memiliki beragam suku dan budaya, tentu tidak mengherankan jika Indonesia kaya akan ragam adat istiadat perihal perkawinan. Sehingga sangat memungkinkan setiap suku memiliki sisi unik tersendiri, seperti yang ditemui pada suku Banjar, di mana masyarakatnya cukup mementingkan adanya sebuah hadiah atau jujuran perkawinan yang diberikan dari calon mempelai laki-laki kepada calon mempelai perempuan. Kemudian, momen kesepakatan tentang jujuran ini akan menentukan dari kelanjutan hubungan maupun acara pinangan tersebut. Hal yang menjadi unik adalah walaupun hadiah atau jujuran ini berasal dari pihak laki-laki, namun besaran nilai hadiah atau jujurannya ditentukan oleh pihak perempuan dan ini bernilai wajib dipenuhi oleh pihak laki-laki yang ingin mempersunting gadis Banjar, yang dikenal religius, ramah, dan santun.

Oleh sebab itu, di dalam teks Madihin tertuangkan guyonan pemadihin atau orang yang bermadihin, "Munnya ulun bulik bisa tajual pahumaan" yang artinya, jika pulang bisa terjual pesawahan. Hal ini menyiratkan bahwa untuk mempersunting gadis Banjar itu memerlukan biaya yang cukup lumayan nilainya, sehingga tidak jarang banyak masyarakat Banjar yang untuk menikah saja, harus menjual sawah. Namun, hal tersebut tidak terjadi jika calon mempelai laki-laki adalah orang yang sudah mapan memiliki pengasilan yang cukup atau dari kalangan orang berada. Sisi unik lainnya adalah seringkali jika gadis Banjar yang ingin dipersunting memiliki kelebihan lain, misalnya berpendidikan tinggi, maka kisaran nilai hadiah atau jujuran juga akan meningkat dan hal ini masih sangat dipercaya oleh masyarakat Banjar.

Data 2 Tema "Pagelaran Seni Desa Alalak"
Karya Alfarizi

Assalammualaikum ulun mangucap salam Buat hadirin hadirat sabarataan

Para masyarakat panonton sakalian

Baik yang dikiri dimuka belakang wan kanan

Yang memperhatikan awan yng sambil bamamakan

Supaya meriah mari bertepuk tangan

Salam sejahtera untuk kita sekalian

Malam ini sangat gembira perasaan

Pagelaran seni yang lagi kita saksikan

Desa Alalak yang menyelenggarakan

Generasi muda harus cinta kesenian

Agar seni kita kada punah sampai ditelan zaman

Sedikit cerita tentang sebuah kota

Yang bergelar kota seribu sungainya

Yaitu Banjarmasin ini nama mashurnya

Di kota tersebut banyak keseniannya

Ada balamut syair juga mamanda

Yang paling terkenal ini madihinya

Kalau ditonton pasti berbahagia

Karena lucu ini pertunjukannya

Wahai masyarakat yang ada di sini
[Assalamualaikum saya ucapkan salam]

[Buat hadirin hadirat semuanya]

[Para masyarakat penonton semuanya]

[Baik yang di kiri di depan belakang dan kanan]

[Yang memperhatikan dan yang sambil makan-makan]

[Supaya meriah mari bertepuk tangan]

[Salam sejatera untuk kita sekalian]

[Malam ini sangat senang rasanya]

[Pagelaran seni yang sedang kita saksikan]

[Desa Alalak yang menyelenggarakan]

[Generasi muda harus cinta kesenian]

[Agar seni kita tidak punah ditelan zaman]

[Sedikit cerita tentang sebuah kota]

[Yang bergelar kota seribu sungai]

[Yaitu Banjarmasin ini nama mashurnya]

[Di kota tersebut banyak keseiannya]

[Ada balamut syair juga mamanda]

[Yang paling terkenal ini madihinnya]

[Jika dilihat pasti bahagia]

[Karena lucu ini pertunjukannya]

[Wahai masyarakat yang ada di sini] 
Terkuhusu nya pemuda dan pemudi Mari semua nya ini kita sadari Budaya kita sudah mulai terganti Dengan budaya orang asing luar negri Contoh nya saja kita lihat sehari-hari Para wanita ini sudah berani Berpakaian kentat yang liwar seksi Rambut inya merah ini diwarnai Lipstik tebal liwar sampai kapipi Budaya Banjar ini kental sekali

Terhadap itu nilai-nilai islami Juga terhadap nilai padatuan bahari Setiap kesenian atau sastra sini Pasti mengandung nasihat untuk diri Agar bermanfaat buat sehari-hari

Batarus madihin ulun mambawa akan Para penonton sudah mulai berdatangan Untuk menyaksikan inilah kesenian Ada yang datang dengan sekeluargaan Ada juga yang dengan pacaran Tapi kasian yang datang sendirian Katahuan jomblo kada singpayuan Sedikit pesan ini gasan kakanakan Bubuhan ikam bermacam kelakuan Apalagi ini nang lalakian

Bakalikiran sambil bakunyungan Mandi disungai bacabur kacamplungan Bakunyung kada sing salawaran Inya bakamih iwak saluang matian Mun ada buntal aku kada tahu ikam Cagar hilang kapala burung ikam

Warisan budaya ini dari nusantara Madihin banjar ciptaan urang banua Sebagai hiburan rakyat disekitarnya Yang selalu ada disetiap acara

Di dalamnya terdapat sebuah makna Seperti nasihat buat pendengarnya Juga ada lucu lucunya jua

Dengan tujuan maulah panuntun tatawa

Sampai disini ulun bamadihinan Salah khilaf mohon di maaf akan Apabila ada kata yang kurang berkenan Akhir kata ulun bapapantunan Burung curian burung cendrawasih Cukup sekian dan terimakasih
[Terkhususnya pemuda dan pemudi]

[Mari semuanya ini kita sadari]

[Budaya kita sudah mulai terganti]

[Dengan budaya orang asing luar negeri]

[Contohnya saja kita lihat sehari-hari]

[Para wanita ini sudah berani]

[Berpakaian kentat yang sangat seksi]

[Rambut dia merah ini diwarnai]

[Lipstik sangat tebal sampai ke pipi]

[Budaya Banjar ini kental sekali]

[Terhadap itu nilai-nilai islami]

[Juga terhadap tradisi nenek moyang dahulu]

[Setiap kesenian atau sastra sini]

[Pasti mengandung nasihatuntuk diri]

[Agar bermanfaat buat sehari-hari]

[Selanjutnya madihin saya bawakan] [Para penonton sudah berdatangan]

[Untuk menyakiskan inilah kesenian]

[Ada yang datang dengan keluarga]

[Ada juga yang dengan kekasihnya]

[Tapi kasihan yang datang sendirian]

[Ketahuan jomblo tidak laku-laku]

[Sedikit pesan ini untuk anak-anak]

[Kalian bermacam tingkah laku]

[Apalagi ini yang laki-laki]

[Berkeliaran sambil berenang-renang]

[Mandi di sungai masuk ke dalam air]

[Berenang tidak pakai celana]

[Dia kencing ikan Seluang mati semua]

[Jika ada Buntal aku tidak tahu]

[Bisa hilang kepala burung kamu]

[Warisan budaya ini dari nusantara]

[Madihin Banjar ciptaan orang Banua]

[Sebagai hiburan rakyat di sekitarnya]

[Yang selalu ada di setiap acara]

[Di dalamnya terdapat sebuah makna]

[Seperti nasihat buat pendengarnya]

[Juga ada humornya]

[Dengan tujuan membuat penonton tertawa]

[Sampai di sini saya bermadihin]

[Salah khilaf mohon dimaafkan]

[Apabila ada kata yang kurang berkenan]

[Akhir kata saya ingin berpantun]

[Burung curian burung cenderawasih]

[Cukup sekian dan terima kasih]

Dari sajian data 2 nilai budaya yang tergambar dalam bahasa dan tertuang pada teks dapat dijelaskan sebagai berikut. 


\title{
c. Bentuk kesenian
}

Pada data 2 tergambar beberapa bentuk kesenian masyarakat Banjar tepatnya pada bait ketiga:

\author{
“...Yaitu Banjarmasin ini nama mashurnya \\ Di kota tersebut banyak keseniannya \\ Ada balamut syair juga mamanda \\ Yang paling terkenal ini madihinya..."
}

Dari teks tersebut dapat terlihat jelas ada beberapa bentuk kesenian Banjar seperti balamut, syair, mamanda, serta Madihin yang sampai saat ini masih sangat populer di kalangan masyarakat Banjar. Kesenian-kesenian ini sangat lekat dengan kehidupan masyarakat Banjar, serta masih terus dijaga kelestariannya. Hal ini dapat dilihat dari berbagai pentas kesenian Banjar yang masih sering dilakukan dan menampilkan berbagai kesenian seperti mamanda, madihin, lamut dan sebagainya. Untuk Madihin, justru masih sangat sering dipertunjukkan pada acara perkawinan-perkawinan sebagai bentuk hiburan sekaligus pemberian pesan nasihat-nasihat kepada kedua mempelai. Bentuk-bentuk kesenian ini selain bertujuan untuk memberikan hiburan kepada masyarakat, juga sebagai cara untuk melestarikan nilai-nilai budaya nenek moyang melalui suguhan seni baik berupa nasiat-nasihat kehidupan, norma-norma agama, mata pencarian, dan sebagainya. Tentu hal ini dapat memberikan kemudahan bagi masyarakat Banjar untuk terus melestarikan segala bentuk peninggalan nenek moyang dan membantu mereka dalam menjalankan kehidupan sehari-hari.

\section{d. Budaya Sungai Banjarmasin}

Pada data 2 juga tergambar tentang budaya sungai masyarakat Banjar yang tertulis pada bait ketujuh.

$$
\text { "... }
$$

Bakalikiran sambil bakunyungan

Mandi disungai bacabur kacamplungan ..."

Pada teks tersebut tersirat bagaimana masyarakat Banjar memang sangat dekat dengan sungai. Banjarmasin dikenal dengan kota seribu sungai, sehingga pemukiman dan aktivitas masyarakat Banjar memang sangat dekat dengan sungai. Oleh sebab itu, mayarakat Banjar memiliki budaya sungai yang mewadahi aktivitas dahulu hingga sekarang, sehingga tidak mengherankan lagi jika anak-anak Banjarmasin begitu dekat dengan sungai. Sungai dijadikan tempat bermain yang sangat menyenangkan bagi mereka. Dengan demikian budaya sungai yang masih sangat melekat pada masyarakat Banjar seperti pemukiman, perdagangan (mata pencaharian), transportasi, dan tempat-tempat wisata yang sangat dekat dengan sungai.

Masyarakat Banjar memiliki pemukiman yang di bawahnya adalah rawa atau sungai, sehingga rumah-rumah masyarakat Banjar memiliki tongkat yang cukup tinggi. Kehidupan masyarakat Banjar memang tidak terlepas dari sungai, sungai dapat membantu mereka dalam menjalani kehidupan sehari-hari pada masanya. Selanjutnya, perdagangan atau mata pencaharian masyarakat Banjar juga tidak jauh dari sungai. Hal ini dibuktikan dengan adanya pasar terapung yang sampai saat ini masih ramai, bahkan menjadi tempat wisata yang menarik untuk dikunjungi di Banjarmasin Kalimantan Selatan. Perihal transportasi, masih ada sebagian masyarakat Banjar yang alat trasnportasi utamanya tidak bisa menggunakan transportasi darat, 
sehingga hanya dapat ditempuh dengan transportasi air, misalnya dengan kelotok atau perahu kecil dengan mesin yang berbunyi nyaring. Hal tersebut membuat beberapa masyarakat lebih memilih memiliki kelotok atau sampan yang didayung daripada memiliki kendaraan bermotor. Oleh sebab itu, dapat dikatakan bahwa sungai merupakan nadi bagi masyarakat Banjar. Meskipun kini sebagian telah berubah karena perkebangan zaman, namun sungai tetap menjadi primadona Kalimantan Selatan dan tetap dijaga kelestariannya. Sungai banyak menyimpan budaya urang Banjar, baik pada masa lalu, kini, dan masa yang akan datang.

\section{e. Nilai Budaya sistem kekerabatan}

Pada teks madihin data 2 ditemukan bentuk nilai budaya sistem kekerabatan. Hal ini ditunjukkan pada teks madihin bait ketujuh baris kedua "...Bubuhan ikam bermacam kelakuan..." kata bubuhan tersebut memberikan petujuk bahwa masyarakat Banjar memiliki sistem kekerabatan yang sangat baik dengan sesama tanpa membedakan status sosial. Dalam konsep kata bubuhan terkandung konsep nilai bedingsanakan atau bisa diartikan persaudaraan, sedangkan batutulungan artinya saling tolong-menolong, mau saling memberi dan menerima. Pada konteks itu pemadihin memberikan nasihat kepada penonton untuk semua jangan berperilaku yang tidak baik dan sebaiknya semua bisa saling menjaga budaya peninggalan leluhur agar tetap lestari dan menjada nilai-nilai yang ada dalam menjalankan kehidupan sehari-hari. Hal ini merupakan bentuk kepedulian pemadihin kepada seluruh penonton yang telah dianggapnya sebagai dingsanak (saudara) untuk saling mengingatkan yang baik untuk semuanya.

\section{f. Sistem Bahasa}

Dari kedua data teks madihin data 1 dan data 2 sama-sama menggunakan bahasa Banjar, hal ini menunjukkan bahwa bahasa yang digunakan dalam interaksi sehari-hari masyarakat Banjar adalah dengan menggunakan bahasa Banjar. Ini juga merupakan bentuk pelestarian masyarakat Banjar akan bahasa ibu mereka. Meskipun kini perubahan zaman sangat pesat, banyak budaya asing bermunculan dengan diikuti dengan bahasa-bahasa baru lainnya, namun masyarakat Banjar masih cukup konsisten dengan terus berusaha menggunakan bahasa ibu dalam setiap kesempatan.

\section{Simpulan}

Berdasarkan hasil kajian mengenai makna nilai etnik dalam teks madihin Kalimantan Selatan, maka dapat disimpulkan bahwa dalam teks madihin Kalimantan Selatan ditemukan nilai budaya menghargai dan saling menghormati, tradisi berpikir tentang hadiah atau jujuran perkawinan, bentuk kesenian, budaya sungai Banjarmasin, sistem kekerabatan, dan sistem bahasa. Semua bentuk nilai budaya yang tergambar melalui bahasa di dalam teks madihin Kalimantan Selatan adalah bentuk ekspresi masyarakat Banjar dalam kehidupan sehari-hari yang memang sangat melekat, menjadi tradisi dan masih dilakukan oleh masyarakat Banjar di Kalimantan Selatan. Dengan demikian, penelitian ini selain memberikan pengetahuan tentang nilai etnik yang terselip dalam teks Madihin, juga sebagai bentuk pelestarian nilai-nilai budaya masyarakat Banjar dalam lingkup kelimuan kajian sastra dan budaya khususnya kebudayaan Banjar. 


\section{Referensi}

[1] Rafiek M. Pantun Madihin: Kajian Ciri, Struktur Pementasan, Kreartiviti Pemadihinan, Pembangunan, dan Pembinaannya di Kalimantan Selatan. J Pendidik Bhs Melayu 2016;2:104-14.

[2] Leha N. Kajian Nilai Religius pada Madihin Karya John Tralala. Pros. Semin. Nas. Bhs. dan Sastra Indones., vol. 1, 2018.

[3] Widiyanti W, Wadiyo W, Sunarto S. Madihin Ar Rumi: Kreativitas Musik dan Tindakan Sosial Dalam Penyajiannya. Catharsis 2016;5:107-13.

[4] Muhlisin A, Gandhi AI, Arfiani SN. Makna syair madihin baintan kebudayaan Banjarmasin menggunakan pendekatan strukturalisme. Fon J Pendidik Bhs Dan Sastra Indones 2018;13.

[5] Sulistyowati E, Ganie TN. Sastra Banjar genre lama bercorak puisi. Tuas Media; 2013.

[6] Effendi R. Sastra Banjar: Teori dan Interpretasi. Banjarbaru Scr Cendikia 2011.

[7] Hasuna K, Lismayanti H. Madihin sebagai kesenian tradisional bagi masyarakat Banjar. Lentera J Pendidik 2017;12.

[8] Hasan R. Linguistics, language, and verbal art. Deakin University; 1985.

[9] Bustan F. Makna Lagu Ara Dalam Ritual Penti Pada Guyup Tutur Etnik Manggaraian Di Flores 2008.

[10] Sahril S. Tradisi akikah masyarakat Melayu pentas sastra lokal "syair nyanyian anak" dalam kajian etnopuitika. JENTERA J Kaji Sastra n.d. https://doi.org/10.26499/jentera.v3i1.433.

[11] Sherzer J, Woodbury AC. Native American discourse: Poetics and rhetoric. Cambridge University Press; 1987.

[12] Pattipeiluhu L, Yuwana S, Muhsyanur M. Ekspresi Etnik Dalam Kapata Masyarakat Alifuru di Maluku Tengah (Kajian Etnopuitika). Elit J Int J Educ Lang Lit 2018;1.

[13] Subrata H. Etnopuitika religi dan dakwah kultural "Syi'ir Suroboyoan" KH Moentowi. Konf Int KESUSASTRAAN XXVII n.d.:354.

[14] Kadarisman AE. Sketsa puitika Jawa: Dari rima anak-anak sampai filsafat rasa. KARYA DOSEN Fak Sastra UM 2009.

[15] Creswell JW. Penelitian kualitatif \& desain riset. Yogyakarta: Pustaka Pelajar 2015. 